\title{
LUGARES DEMORADOS: CONSTRUCCIÓN, ORIENTACIÓN Y EXPERIENCIA DEL ESPACIO POÉTICO
}

\section{Iker Perez Goiri}

Investigador independiente

\section{Resumen}

El espacio poético se nos presenta como un lugar acotado y diferenciado mediante una acción constructiva de demarcación. En su naturaleza estética, traza y establece estructuralmente, en una operación plástica, el ámbito para la experiencia sensible de lo inefable e incognoscible. El espacio poético funda un mundo y se constituye como punto de orientación: circunscripción del universo y lugar donde acontece el fenómeno estético de la imagen. Mediación entre el sentido corporal y las regiones trascendentes del ser humano, entre lo no-manifestado y la manifestación. Experiencia integrada de realidad y vivencia en un mismo contorno: el mundo imaginal. Hablaremos, por lo tanto, de Lugares demorados, en los que adviene una presencia que rebasa el lenguaje, reclamando una escucha atenta y de absorción contemplativa. Lugares significativos de un presente en el que se demora y hace su morada la realidad de lo vital en el tiempo del suceder.

\section{Palabras clave: ESPACIO POÉTICO; LUGAR; MUNDO IMAGINAL; CON- TEMPLACIÓN; TIEMPO}

\section{LINGERED PLACES: CONSTRUCTION, GUIDANCE AND EXPERIENCE OF POETIC SPACE}

\section{Abstract}

The poetic space appears as a reserved and differenced place, through an action of constructive siting. In its aesthetic nature, it structurally traces and establishes, in a plastic making, the field for the sensible experience of the ineffable and the unknowable. The poetic space founds a world and becomes a point of guidance: circumscription of the universe and place where the aesthetic phenomenon of the image occurs. A link between the bodily senses and the transcendent regions of the human being, between the non-manifested and the manifestation. Integrated fact of reality and experience in the same environment: the imaginal world. We will speak, therefore, of Lingered places, in which appears a beyond language presence, demanding a deep listening and contemplative absorption. Significant places of a present tense, in which a vital reality lingers and dwells, in the time of happening.

\section{Keywords: POETIC SPACE; PLACE; IMAGINAL WORLD; CONTEMPLA- TION; TIME}

\footnotetext{
Perez Goiri, Iker. 2020. "Lugares demorados: Construcción, orientación y experiencia del espacio poético". AusArt 8 (2): 165-177. D0I: 10.1387 /ausart.22009
}

\section{AUSART}


Formo

de tierra y de saliva un hueco, el único

que pudo al cabo contener la luz.

José Ángel Valente.

- ¿Por qué quieres ser arquitecto?

- Para crear espacios.

-¿Espacios?

- Sí.

- ¡Los espacios no son más que vacío!

- Vacío que debe llenarse.

-¿De qué?

$-D e$ luz. Y de gente.

-Tienes razón.

Diálogo de la película La Sapienza

(Eugène Green, 2014).

\section{FUNDACIÓN DEL ESPACIO POÉTICO}

Un espacio acotado y diferenciado como lugar de consciencia y potencia de percepción proporciona, antes de toda comprensión, el ingreso en un ámbito consagrado, un marco para el designio: aquello que habrá de ser significativo, abriendo un mundo y volviéndolo sobre la tierra (Heidegger [1952] 2009, 63). El Templum augural trazaba un espacio concreto en la bóveda celeste y el Témenos griego definía un lugar separado, en ambos casos haciendo presente un acontecimiento de realidad más significativa y como territorio de manifestación. El espacio poético, en este mismo planteamiento, se habría de trazar y definir como lugar de experiencia y de sentido. Como el área donde algo se in-corpora [toma cuerpo] y se in-forma [viene a la forma] en la organización de una estructura donde pudiera advenir un rostro de aquello indecible, presentándose como tal y permaneciendo inefable. El espacio poético nos remite así a una dimensión trascendente de lo humano, que se hace a la sensibilidad pero que no puede ser pensado ni comprendido. Todo saber aquí sería entonces un no sabiendo: "toda ciencia trascendiendo", como escribía Juan de la Cruz. 
Configurar un espacio poético implicaría, por tanto, establecer estructuralmente un lugar resonante para percibir lo que no puede ser aprehendido directamente, dotándolo así de un corpus para su revelación: lo que des-cubriéndose aparece nuevamente velado en los indicios de lo inconmensurable y no-manifestado, "lo in-decible por decir apenas sugerido", nos recuerda Chantal Maillard $(2010,7)$. Esta realidad que no cabe en el lenguaje, desbordando la razón conceptual, adviene aquí como un rostro: máscara cósmica, en la terminología de Jorge Oteiza. Y lo hace en tanto que materia a contemplar, utilizando las palabras con las que Kosme de Barañano (citado en Tucker $2015,54)$ se refiere a las piedras colocadas en vertical tanto en los crómlech, menhires o dólmenes, y que son fundadoras de un territorio, de una geografía primera, y de una orientación para la consciencia. Piedras erigidas, edificadas, presencias en sí mismas y que construyen un espacio y lo dotan de vida. Piedras en las que algo se hace, algo se produce: el lugar de la imagen.

Aquella acción primera del paisaje es ya constructiva, porque el espacio poético ha de construirse en una operación de demarcación sustancial y de naturaleza estética. La experiencia trascendente del poema se hace cuerpo y ha de pasar por lo corpóreo para su contemplación y aprehensión sensible. Como nos recordaba Paul Cézanne (citado en Gasquet [1921] 2009, 166), el artista ha de ser "un eco perfecto", un receptáculo de sensaciones que han de ser plasmadas en la materia. Esta encarnación a su vez habrá de permitir el florecimiento de un saber, pero un saber silencioso que remita hacia una expansión de la consciencia, para traer con ella la proyección a un orden integrador unificado. La manifestación poética del arte aparece sensiblemente, en su condición plástica. La construcción de la forma [en un modo sin modo] habrá de determinar su contenido, manifestación y acontecimiento. Operación en un orden estructural de la que emerge una plasticoactividad, trayendo consigo un saber que solo se aprehende estéticamente, en el seno de aquel espacio poético en el que radica, en el que hace su morada.

Lo que denominamos arte, en el orden y virtud del poema, se torna así lugar de aparición y espacio donde quedan trazadas las huellas de lo vital: lo que se hace sensible en lo percibido emerge del fondo informe de lo incognoscible. Algo que no puede ser conocido mediante la mente analítica. El saber del arte radicaría en el espacio poético que construye, porque pide su emergencia, y que a su vez es construido para su advenimiento y experiencia. Por lo tanto, podríamos esbozar una definición del espacio poético señalándolo como el lugar in-augurado por una estructura de sentido y actividad plástica, que llamamos poema u obra de arte, y en cuyo seno se acoge y pone su morada, 
estéticamente, un sesgo de lo vital y que es erigido como arquitectura: construcción de un sistema de experiencia sensible que remitiría siempre a un fondo común, el de lo primordial [arkhé].

Este lugar demarca una ruptura con el espacio homogéneo y, al tiempo que funda un mundo, se constituye en punto de orientación. Como afirma José Ángel Valente, "el lugar es el punto o el centro sobre el que se circunscribe el universo" ([1971] 2002, 30), y por ello, un espacio constituido como eje central de un cosmos, un Axis Mundi: donde algo se hace y todo puede comenzar. Porque los puntos cardinales de un territorio existencial revelan un organismo que, saliendo del magma informe [kaos], se descubre como un cosmos: conjunto ordenado, estructurado, de emergencias formales y de presencias fenoménicas. En un cosmos, nos recuerda Mircea Eliade ([1957] 2014, 87), ontofanía y hierofanía se reúnen, es decir, se descubren a la vez las modalidades del ser y la manifestación de lo sagrado. Por ello, en el espacio poético hace aparición aquello que viene a constituirse en imagen: "toda hierofanía espacial o toda consagración de un espacio equivale a una cosmogonía" (ibíd., 51). Con la fundación del espacio poético, el mundo adquiere una existencia concreta, una potencialidad de percepción en tanto que universo emergente, irradiando a su vez hacia todos los órdenes de la vida humana.

Hablamos pues de lugares demorados, en los que adviene una presencia que reclama la escucha atenta y plena del sujeto, trascendiendo el tiempo relativo de los relojes. Lugar donde mora y se de-mora, en un presente integrador, la vida que se vive a sí misma, en un tiempo del suceder, en un acontecer de potencias y fuerzas. Es aquí donde emerge, en palabras de Gilles Deleuze, un "impensado en el pensamiento" ([1985] 2010, 243), algo que acontece con anterioridad al pensar y como límite, en una "puesta en movimiento del alma", como reclamaba Antonin Artaud ([1926] 2002, 48). Un impensado que se aprehende en una corriente de las cosas: "pura y absoluta intensidad de la manifestación antes de entrar en el orden de las significaciones" (Valente, [1991] $2000,61)$. Lugares demorados, pues, en los que se prolonga el vislumbre de la fuente de la que brotan las existencias individuales. Un tiempo de estar siendo en todo y con todo: "el propio movimiento de la vida, su movimiento de crecimiento, de experimentación de sí misma con una fuerza mayor", nos recuerda Michel Henry ([1988] 2008, 32). Lugares de paroxismo vital, de situarse en la confluencia de toda resonancia, o como escribía José Val del Omar: "donde se asienta el latido / de todos los temblores" ([1992] 2012, 25). En los lugares demorados algo aguarda, establece su permanencia siempre renaciente y renovada. 


\section{DEMARCACIÓN Y TRAZADO}

El espacio poético se establece en la integración del acontecer de las cosas y el lugar construido para su percepción y experiencia. Se nos ofrece como posibilidad de orientación porque permite al acontecimiento aflorar en el lugar que le corresponde y a su vez opera una demarcación para su receptividad. Hablaríamos del punto de encuentro entre, por un lado, la observación atenta de los elementos que conforman un universo por sí mismo; y por otro, el establecimiento de los puntos cardinales en el territorio del suceder. Este espacio se configura, en palabras de Chantal Maillard, mediante la actitud acompasada de ver y trazar: "actitud intermedia entre el ver dejando que las cosas ocupen el lugar que les corresponde y el trazar-imaginar, crear-el horizonte adecuado sobre el que puedan hacerse visibles" (1992, 175). Receptividad de la realidad en su estar viva y el fraguar de un espacio para su visibilidad.

Lo invisible e inefable es recogido como acontecimiento sensible para su manifestación. Se establece una red, en tanto que receptáculo, para poder cazarlo al paso: aquello que Oteiza reclamaba del artista cuando lo identificaba como hacedor de trampas. En el espacio poético lo indecible e inconmensurable, en sí mismo incognoscible, aparece como Ser Estético, que se atestigua en esta operación estructural, en la construcción formal de su realidad. Descubrimiento entre la constante receptividad atenta y la acción ejecutante, demarcando el espacio latente desde la acción justa y sustancial. Equilibrio entre el dejar hacer y el acto de hacer, unión entre el observador y lo observado.

Demarcación y orientación para que una realidad pueda exponerse y entregarse a su contemplación. Lugar de escucha y de presencia, de re-unión y unificación: estar en la vida aprehendiéndola en nuevas relaciones y en nuevas formas de existencia. Así sucede, nos indica María Zambrano, en el claro del bosque, que es espacio de apertura y visibilidad, lugar de contacto con la realidad en su estar viva y en su fluencia. Lo que es fugitivo y de difícil concreción adquiere aquí, trazado el cerco, un ámbito de emersión: medio de visibilidad donde "el pensamiento y el sentir se identifiquen sin que anulen." Lugar en el que alborea "una sensibilidad nueva, lugar de conocimiento y de vida sin distinción" (Zambrano [1977] 2011, 124).

Unidad entre pensamiento y vida, que integra al conocimiento en un saber de experiencia, desbordando los límites de la razón discursiva y de las formas enunciativas. Este desbordamiento, al mismo tiempo, las reúne y las atempera en el cauce del fluir de toda realidad poética, reflejando un curso cuyo sentido 
operante es captado al mismo tiempo que es vivido, puesto que, como nos indica Vicente Gallego (2014, 80): "son una misma cosa la realidad y su vivencia”. Por lo tanto, el espacio poético acoge y testimonia realidades de un orden otro al del lenguaje y anteriores al pensamiento, realidades innominables e inmersivas en el corazón y las entrañas de lo absoluto, "porque es la poesía la expresión misma de la vida en su misterio" (Maillard 1992, 28). Realidades que no pueden ser conocidas más que poéticamente y que se manifiestan y residen en el espacio poético, en el poema mismo. Revelación de algo encubierto, de algo oculto a simple vista, de nuevas relaciones de existencia todavía no percibidas, no traídas al campo de consciencia. Lo indecible se muestra tanteado en lo no percibido aún, inmerso en lo no-inteligible, pero aguardando a hacerse sensible, "tan incomprensible como evidente", nos recuerda Antonio Gamoneda, y añade: "las realidades cósmicas se dan así: sensibles" (citado en Janés 2010, 147).

El espacio poético inscribe un lugar en el que, como indica José Ángel Valente ([1971] 2002, 30), "su realidad y su representación no se diferencian". Al mismo tiempo, su cometido no es la significación, puesto que la intensidad de su manifestación es anterior al orden de las significaciones. Nos sitúa entonces en lo tumultuoso de la experiencia, en lo expandido de su vivencia y su indeterminación. Sin embargo, acontece en tanto que realidad plástica encarnada y operante, que incesantemente invoca la complejidad de lo que irrumpe y que trae, en palabras de Jean-Luc Marion, un invisto a lo visible: "lo invisto depende ciertamente de lo invisible, pero no se confunde con él, puesto que puede transgredirlo para devenir precisamente visible" ([1991] 2006, 55). Por tanto, un invisible no visto aún, pero que es invisible de forma provisional y exige su visibilidad, su formación desde lo informe y lo no-visto. Reclama de una puesta en forma mediante la que ascender hacia lo visible y remontarlo en un imprevisto: caer en la cuenta de una nueva realidad hasta ese momento indiscernible.

Este invisto es un fulgor de lo que está siempre en fuga, atravesando el espacio poético en pleno vuelo. Se cumple así la paradoja de crear un lugar que al mismo tiempo permita lo ilimitado: un universo que es reflejo de universos, una mismidad que conecta con la otredad. El espacio poético se dimensiona como vibración liminal, dándose todo a modo de fuerza e impulso y dentro de su lógica [logos] estructural. Con estas palabras daba cuenta de ello Eduardo Chillida: "no veo sino cierta figura de espacio de la que, poco a poco, se destacan algunas líneas de fuerza. La forma al principio es casi como un aroma indefinido que se imprime a medida que va precisándose" ([2005] 2016, 77). 
Es necesario señalar que esta experiencia, que reclama su encarnación, requeriría de una consciencia estética, luz misma de las formas actuantes, captando al mismo tiempo una energía, un aliento en su configuración interna. Consciencia pre-reflexiva, nos dice Chantal Maillard, que otorga las pautas para la elaboración de todo nuevo mundo, de su organización: "mostrarle a la conciencia aquello que la conciencia parece incapaz de ver cuando no está ordenado en un sistema que permite el reconocimiento" (Maillard [1998] 2017, 20). La demarcación del espacio poético es deudora, en este sentido, de la sensación anterior a su inteligibilidad, tornándose en lo evidente de la imagen, por la cual aquella consciencia pareciera querer conocerse a sí misma. Lo universal se hace así en lo particular, lo infinito fecunda así la finitud de la materia.

El espacio poético es, justamente, lugar de revelación, donde todo es acogido en estado naciente, en una visión que llega para romper la oscuridad del sentido: "la vista que se abre, y que sólo se abre verdaderamente si bajo ella y con ella se abre al par la visión" (Zambrano [1977] 2011, 161). Se descubre aquí una realidad en la correspondencia entre sentido y videncia. Lugar de actividad favorable para la consciencia: "en el que la persona se pone en relación con Dios o en relación política [o religiosa] con los demás", nos recuerda Oteiza ([1963] 2009, apartado 45). Un territorio trazado como lugar de encuentros, de esos encuentros con lo que acontece en dicho espacio significativo, activado mediante su acotación y construcción estética.

\section{MUNDO IMAGINAL}

Localizamos aquí la realización del fenómeno estético que denominamos imagen: mediación entre el sentido corporal y las regiones trascendentes. Un encuentro entre lo no-manifestado e incognoscible con la manifestación y la forma. En dicha operación, la experiencia de la imagen se ofrece como acceso a lo que no se deja pensar, por lo cual nos recuerda Artaud: "lo que es del dominio de la imagen es irreductible por la razón, y debe permanecer en la imagen, so pena de aniquilarse" ([1929] 2005, 87). Nos referimos así al ámbito en el que lo todavía imperceptible se vierte como vislumbre en la percepción y que se nos presenta como el "instante del encuentro entre el mundo exterior y el mundo interior" - nos dice Victoria Cirlot - "[...] Ya no es ni lo irreal ni lo real, sino la síntesis de ambos" $(2010,51)$. Hablamos de ese espacio intermedio 
que Henry Corbin denominó como Mundus imaginalis: la intersección de dos círculos, tierra y cielo, sentidos y espíritu, es decir, el espacio de la mandorla.

El mundo imaginal se descubre como sesgo de la percepción, es apertura y punto de encuentro, y por ello, herida y sutura a la vez. Acontece un mutuo desvelamiento, algo que solo puede aparecer a través de esta incorporación de la imagen en tanto que receptáculo. Así nos lo dice Javier Melloni: "cada imagen es un encuentro de ambas dimensiones a través de ese mismo contorno que se convierte en un umbral, en paso iniciático" $(2018,127)$. En definitiva, un tránsito constante entre lo sensitivo y lo espiritual, entre lo ascendente y lo descendente, interioridad y exterioridad. Melloni advierte de que nos hayamos en el topos de la experiencia visionaria: eclosión que habrá de estar "en la imagen misma, aunque no se agote en ella" (íbid., 128). Las imágenes actuarán entonces como un puente entre dos orillas, trayendo consigo los "atisbos de un fondo que se revela a través de ellas" (íbid., 130).

Por lo tanto, el mundo imaginal se nos presenta como espacio de no-dualidad, situado entre lo subjetivo y lo objetivo. Es así que el conocimiento propio del espacio poético habrá de constituirse como un trampolín hacia una dimensión de receptividad y apertura contemplativa, de lo intemporal en la temporalidad. Javier Melloni nos habla de una ruptura de nivel en la experiencia de la imagen, y con ella, una transfiguración de los sentidos. Habiéndose gestado en este espacio hierofánico, permanece flotante, entre la materialidad y su trascendencia: "revela tanto como oculta, a la vez que unifica al que ve con lo que ve" (Melloni 2018, 139). Los fenómenos así revelados, en consecuencia, descubren constelaciones y rumbos, órdenes de sentido y orientaciones. Los objetos sensibles son mediadores, posibilitando el alcance de toda percepción física hacia las regiones mistéricas de la experiencia poética.

En consecuencia, podemos recurrir, como lo hace Ken Wilber ([1983] 2010, 13), a los tres ámbitos de percepción y conocimiento planteados por San Buenaventura en el siglo XIII y que nos permiten discernir y aproximarnos a este proceso de aprehensión de la realidad en sus distintas dimensiones. San Buenaventura habla de los tres ojos: un primero que es el de la carne, el de los sentidos exteriores, que revelan a partir del mundo percibido un universo de experiencia sensorial y una actividad de lo sensible a través de la aprehensión material y plástica. Un segundo ojo, el de la razón, que corresponde a la percepción interior, donde acontecen los procesos y operaciones de lo sutil, la revelación como imago, la elaboración psíquica y del alma, operando a su vez los procesos de pensamiento y lógica. Y el tercero, el ojo de la contempla- 
ción, que es el sentido mediante el cual adquirimos un acceso a las realidades trascendentes, donde se aprehende lo inefable: un saber que no se sabe sabiendo. La contemplación acontece como inenarrable y es el lugar en el que se asienta y se hace presente la consciencia. Exterioridad e interioridad quedan aquí unificados y transmutados en una realidad que, nos indica Wilber, es paradigma de lo transpersonal, y que precisa de la integración de los tres ojos o sentidos para su plena aprehensión y funcionalidad.

El espacio poético permite y despliega el lugar para dicha operación a partir de las realidades sensoriales y sensibles de la plástica y la materialidad como envolturas de lo inefable. Se dispone así el salto a los procesos del alma humana, a la percepción entrañada, realidad intuitiva y cordial, para zambullirse en su absorción. Es así que en el espacio poético se opera el "nacimiento del espíritu a partir de la materia", y de esta forma, observamos "la función del arte como comadrona de este parto" (Wilber [1983] 2010, 164). Nexo entre lo individual y lo universal: comunión en la que se descubren nuevos aspectos y dimensiones de la realidad, con un fondo innominado e innominable, ensanchando "los límites de lo personal hacia lo transpersonal" (íbid., 166). Esta entrega permite una atención y un conocimiento expandido, capaz descubrir en el cuerpo poemático un curso de lo que siempre es igual a sí mismo y que es renovado en cada estructura y en cada plástica. Una atención a lo que se muestra revelado, siendo el sujeto testigo de lo que en toda forma adquiere presencia en tanto que no-forma, presencia aquí demorada de lo inabarcable.

\section{LUGARES DEMORADOS}

Lo indecible que hace su morada estética en las formas reclama así esta atención contemplativa. Vigilancia hacia lo que se establece y habita como presencia, en tanto que fondo último acogido y trazado en lo físico. El hecho poético requiere e invoca esta atención demorada hacia dicho estado de espaciosidad consciente, de saber que fructifica silenciosamente. Materia fecundada de aquello inmutable y pleno en su no-distancia con el conjunto de lo real. No sujeto a lo impermanente, pero que posibilita su vivencia en el saboreo de su aparición.

Nos encontramos así con esta realidad de lugares demorados. En ellos se dilata esta presencia, quedando retenido un indicio, un aroma, una brizna 
entrando en la materia. Algo que, desde la receptividad primera y dispuesta de la percepción corpórea, abre un fondo que se despliega hacia el abismo: reunión de las entrañas del alma con la extensión de lo absoluto. Lo que rebasa al sujeto y al mismo tiempo lo fundamenta desde dentro, la unidad en lo diverso. Si bien nos hemos referido a ello sucintamente con anterioridad, es importante señalar que esta trascendencia no se opone a lo corpóreo y a lo psíquico, sino que integra y unifica las dimensiones carnales y mentales, que no le resultan ya contradictorias ni opuestas. Quedan establecidas y situadas en el lugar que les corresponde, observadas en todo momento en un continuo no-dual.

En los lugares demorados interviene esta actitud testimonial: "todo lo que está presente puede estar presente", como indica Franz Jalics ([1994] 2017, 32). Por tanto, una disponibilidad de dejarlo vivir, de percibir la sensación en su claridad y registrarla, llevándola al centro de la atención. Observar lo que fluye desde la aparición de esa realidad concreta y disponible, dejando actuar dicha percepción sobre la sensibilidad. Captar y recibir sin detenerse en la pregunta por el significado ni el sentido. La pregunta es una operación mental y el sentido habrá de llegar por sí mismo, inherente a la experiencia. Percibir, por tanto, lo que hay y lo que acontece. Prestar atención no ingresando directa y definitivamente en el lenguaje ni en los pensamientos, sino dejándose arrastrar por el asombro y la impresión de lo que emerge. Quedarse en el no-entendiendo, en el no-saber. Por ello, como advierte Jean-Claude Rousseau, la imagen no dice nada, sino que antes hace callar: "de alguna manera arrebata la palabra" (2008, 24-5).

Constatamos efectivamente que la operación misma de la imagen consistiría en hacer presente, núcleo de un sobrecogimiento: afectación ante lo irrepresentable que aparece revestido en lo imaginal. Esta presencia se hace consciente de sí misma en las formas que la manifiestan, que la expresan. Tiene su fluencia y trae consigo su propio tiempo. Un tiempo que no será otro más que el de su mismo acontecimiento, un tiempo significativo que constantemente se actualiza y que los antiguos griegos denominaron Kairós. Situado en la encrucijada entre lo mensurable y lo inconmensurable, establece la convergencia entre lo cronológico [Kronos] y lo eterno [Aión o Eón]. Un tiempo kairológico, alboreando siempre en el suceder: "¿Tiempo? Otro tiempo. El de los relojes, no; nada que solidifique las fuerzas. Un tiempo que permita acontecer entre todos y, a la vez, dar cuenta de ello", nos dice Chantal Maillard $(2008,35)$. Atención y aprendizaje de un ritmo, situándose en las trayectorias de este devenir de fuerzas. 
Una temporalidad que se funda en las estructuras del espacio poético, en el lugar demorado que se abre como presente continuo de las formas. Un instante que se demora: "cada momento de tiempo existe en el contexto del ahora, el eterno ahora”, nos dice Nathaniel Dorsky ([2003] 2016, 35). Para ilustrar esta experiencia entre el presente eterno y el tiempo cronológico, propone la metáfora de una cinta ergométrica: "el ahora es tu presencia, mientras que el tiempo relativo pasa bajo tus pies" (ibíd.). Por esta razón, en el tiempo relativo se revela una corriente continua, un presente activo. Un tiempo de lo atemporal que trasciende la horizontalidad cronológica de lo que constantemente pasa sin detenerse. El fruto de estos lugares demorados es un instante en tanto que inmensidad del tiempo, lugar de todo tiempo posible. En palabras de José Val del Omar (2010, 307): “ante lo inmenso no cabe el reloj. Empieza por tirar tu reloj al agua". El tiempo del reloj se hunde en la realidad de las aguas oceánicas de un tiempo otro. Lugar de fluctuaciones, de estratos temporales, contracciones y expansiones, convergencias y disoluciones.

Este presente contiene en sí tanto el pasado como el futuro en su propia duración: "el pasado y el futuro de una forma están sucediendo en el presente mismo de ella", nos recuerda Oteiza ([1944] 2007, 295). Estas tres capas de tiempo convergen en el instante de los lugares demorados: niveles distintos de percepción que se integran en la confluencia de diversos estratos de actividad, desplegándose en un presente fecundo, flotante y durable. Un presente que es el tiempo propio de la imagen y que nos sitúa en su duración. El espacio poético alberga una temporalidad: "el tiempo es la conciencia propia de la obra que, al vivirla, nos es revelada en su idioma universal, que es necesario aprender a leer" (ibíd., 296). En este tiempo estético se demora la presencia de lo imaginal, y en consecuencia, no es nuestro tiempo lo que llevamos al espacio poético, sino que en él encontramos el suyo, nos conduce a su lógica y su acontecer. Los lugares demorados son el trazado para esta presencia, la construcción estéticamente activa para la experiencia poética.

\section{Referencias bibliográficas}

Artaud, Antonin. (1926) 2002. El pesa-nervios. Versión, prólogo y notas de Marcos Ricardo Barnatan. Madrid: Visor

- . (1929) 2005. El arte y la muerte; Otros escritos. Traducción, Víctor Goldstein; prólogo, Esteban lerardo. Buenos Aires: Caja Negra

Chillida, Eduardo. (2005) 2016. Escritos. Selección de textos, edición y coordinación, Nacho Fernández Rocafort. Madrid: La Fábrica 
Cirlot Valenzuela, Victoria. 2010. La visión abierta: Del mito del Grial al surrealismo. Madrid: Siruela

Deleuze, Gilles. (1985) 2010. La imagen-tiempo. Estudios sobre cine 2. Traducción de Irene Agoff. Madrid: Paidós

Dorsky, Nathaniel. (2003) 2016. El cine de la devoción. Trad., Miguel García. Barcelona: Lumière

Eliade, Mircea. (1957) 2014. Lo sagrado y lo profano. Traducción de Luis Gil Fernández \& Ramón Díez Aragón. Barcelona: Paidós

Gallego Barrado, Vicente. 2014. Vivir el cuerpo de la realidad: Los tres alcances del abrazo sincero. Barcelona: Kairós

Gasquet, Joachim. (1921) 2009. Cézanne: Lo que vi y lo que me dijo. Traducción de Carlos Manzano. Madrid: Gadir

Heidegger, Martin. (1952) 2009. Arte y poesía. Traducción y prólogo de Samuel Ramos. Ciudad de México: Fondo de Cultura Económica

Henry, Michel. (1988) 2008. Ver lo invisible: Acerca de Kandinsky. Traducción del francés de María Tabuyo \& Agustín López. Madrid: Siruela

Jalics, Franz. (1994) 2017. Ejercicios de contemplación: Introducción a la vida contemplativa y a la invocación de Jesús. Traducción, Beatriz Romero \& Helga Heineken. Salamanca: Sígueme

Janés Nadal, Clara. 2010. Variables ocultas: Con dos cartas de Antonio Gamoneda. Madrid: Vaso Roto

Maillard, Chantal. 1992. La creación por la metáfora: Introducción a la razón poética. BarceIona: Anthropos

— . (1998) 2017. La razón estética. Barcelona: Galaxia Gutenberg

— . 2008. En la traza: Pequeña zoología poemática [In the tracing: Small poetic zoology]. Traducción, Julie Wark. Barcelona: Centre de Cultura Contemporània de Barcelona

Maillard, Chantal. 2010. El no saber cargado de compasión: Conversación con Chantal Maillard. Entrevista de Laura Giordani, Arturo Borra \& Víktor Gómez. Madrid: Fundación Inquietudes

Marion, Jean-Luc. (1991) 2006. El cruce de lo visible. Traducción de Javier Bassas Vila \& Joana Masó. Castellón: Ellago

Melloni Ribas, Javier. 2018. Perspectivas del absoluto: Una aproximación místico-fenomenológica a las religiones. Barcelona: Herder

Oteiza, Jorge. (1944) 2007. Interpretación de la estatuaria megalítica americana: Carta a los artistas de América sobre el arte nuevo en la postguerra. Coord. y responsable de la edición María Teresa Muñoz en colaboración con Joaquín Lizasoain \& Antonio Rubio; traductor al euskera, Pello Zabaleta Kortaberria. Alzuza: Fundación Museo Jorge Oteiza

- . (1963) 2009. Quosque tandem...! Ensayo de interpretación estética del alma vasca. Pamplona: Pamiela

Rousseau, Jean-Claude. 2008. "Entrevista con Jean-Claude Rousseau: 'La vallée close'". Por Cyril Neyrat; traducción del francés, Francisco Algarín Navarro. Elumiere.net. http://elumiere.net/especiales/Rousseau/01_web/01_Rousseau.php

Tucker, William. 2015. Tucker: Masa y figura; 9 de junio-14 de septiembre de 2015. Textos, Kosme de Barañano. Bilbao: Museo de Bellas Artes de Bilbao 
Val del Omar, José. (1992) 2012. Tientos de erótica celeste. Selección y adaptación, Gonzalo Sáenz de Buruaga y María José Val del Omar; prólogo, Luis García Montero. Granada: Diputación de Granada

- . 2010. Escritos de técnica, poética y mística. Edición a cargo de Javier Ortiz-Echagüe; prólogo de Santos Zunzunegui. Barcelona: Ediciones de La Central

Valente Docasar, José Ángel (1971) 2002: Las palabras de la tribu. Barcelona: Tusquets

- . (1991) 2000. Variaciones sobre el pájaro y la red; precedido de La piedra y el centro. Barcelona: Tusquets

Wilber, Ken. (1983) 2010. Los tres ojos del conocimiento: La búsqueda de un nuevo paradigma. Traducción de David González Raga. Barcelona: Kairós

Zambrano Alarcón, María. (1977) 2011. Claros del bosque. Edición de Mercedes Gómez Blesa. Madrid: Cátedra

(Artículo recibido: 15-09-20; aceptado: 02-11-20) 